\title{
Effect of recombinant Lactococcus lactis producing myelin peptides on neuroimmunological changes in rats with experimental allergic encephalomyelitis
}

\author{
Kaja Kasarełło ${ }^{1,2^{*}}$, Agnieszka Szczepankowska ${ }^{3^{*}}$, Barbara Kwiatkowska-Patzer ${ }^{2}$, Andrzej W. Lipkowski², \\ Roman Gadamski ${ }^{4}$, Dorota Sulejczak ${ }^{5}$, Magdalena Łachwa ${ }^{6}$, Michał Biały ${ }^{1}$, Jacek Bardowski ${ }^{3}$ \\ *These authors contributed equally to this study \\ ${ }^{1}$ Department of Experimental and Clinical Physiology, Laboratory of Centre for Preclinical Research, Medical University of Warsaw, \\ ${ }^{2}$ Department of Neuropeptides, Mossakowski Reaserch Center, Polish Academy of Sciences, Warsaw, ${ }^{3}$ Institute of Biochemistry \\ and Biophysics, Polish Academy of Sciences, ${ }^{4}$ Department of Clinical and Experimental Neuropathology, Mossakowski Medical \\ Research Centre, Polish Academy of Sciences, ${ }^{5}$ Department of Experimental Pharmacology, Mossakowski Medical Research Centre, \\ Polish Academy of Sciences, 'Laboratory of Advanced Microscopy Techniques, Mossakowski Medical Research Centre, \\ Polish Academy of Sciences, Poland
}

\begin{abstract}
Multiple sclerosis (MS) is a human autoimmune neurodegenerative disease with an unknown etiology. Despite various therapies, there is no effective cure for MS. Since the mechanism of the disease is based on autoreactive $T$-cell responses directed against myelin antigens, oral tolerance is a promising approach for the MS treatment. Here, the experiments were performed to assess the impact of oral administration of recombinant Lactococcus lactis producing encephalogenic fragments of three myelin proteins: myelin basic protein, proteolipid protein, and myelin oligodendrocyte glycoprotein, on neuroimmunological changes in rats with experimental allergic encephalomyelitis (EAE) - an animal model of MS.

Lactococcus lactis whole-cell lysates were administered intragastrically at two doses $\left(10^{3}\right.$ and $10^{6}$ colony forming units) in a twenty-fold feeding regimen to Lewis rats with EAE. Spinal cord slices were subjected to histopathological analysis and morphometric evaluation, and serum levels of cytokines (IL-1b,IL-10, TNF- $\alpha$ and IFN- $\gamma$ ) were measured. Results showed that administration of the $L$. lactis preparations at the tested doses to rats with $E A E$, diminished the histopathological changes observed in EAE rats and reduced the levels of serum IL-1b, IL-10 and $T N F-\alpha$, previously increased by evoking EAE. This suggests that oral delivery of L. lactis producing myelin peptide fragments could be an alternative strategy to induce oral tolerance for the treatment of MS.
\end{abstract}

Key words: MS, autoimmunity, oral tolerance, Lactococcus lactis, EAE, myelin proteins. 


\section{Introduction}

Multiple sclerosis (MS) is an autoimmune disease that targets young people (20-40 years old) and is more common in women than in men. It is most frequently encountered in Northern Europe and North America, affecting approximately 1 in 1000 people. The genesis of MS remains unknown, but some evidence has supported the contributions of genetic and environmental factors or viral infection [35]. Despite its unidentified origin, the mechanism of MS involves humoral and cellular immunity and is based on T-cell autoreactivity directed against myelin antigens. Autoreactive T-lymphocytes migrate through the open blood-brain barrier into the central nervous system (CNS), where they recognize myelin proteins as pathogenic and induce an antigen-specific inflammatory process. Inflammation directed against myelin proteins causes demyelination and further deterioration of axons or even whole neurons, which results in deceleration or disruption of neurotransmission [12]. Tissue injury also affects oligodendrocytes function due to glutamatergic excitotoxicity in the sites of inflammatory lesions [10]. CNS damage provokes progressive physical disability and associated mental impairment that occur in MS patients. Currently, there is no effective therapy for MS. The most common treatment is systemic immunosuppression, which may also weaken the immune system and expose the patient to frequent infections $[3,12,42]$. However, new therapies targeting specific mechanisms involved in the pathology of MS, such as natalizumab, alemtuzumab or daclizumab may cause severe side effects or result in lower efficiencies than previously expected [7-9]. Thus, there is a need to identify novel therapies that are more effective and safe for patients. Among the most promising approaches developed in recent years that could potentially be applied for the treatment of autoimmune diseases is the induction of oral tolerance [11].

Oral tolerance is a natural state of a decreased immunoresponse to the previously fed antigen. The mechanism induces tolerance toward ingested antigens, which are normally encountered in the body (e.g. commensal bacteria, food). The phenomenon of oral tolerance has been applied for ovalbumin-induced anaphylaxis, contact hypersensitivity or the suppression of antibody production. The same approach has been also proposed for the treatment of autoimmune diseases, and many preclinical trials, including MS therapy, have been conducted $[11,37,38]$. In most of those trials, myelin basic protein (MPB) or its fragments served as the antigen, and all were shown to reduce the clinical symptoms of induced experimental allergic encephalomyelitis (EAE) $[15,26]$. However, MBP is not the only antigen that is considered to be immunogenic in MS. Antibodies directed against proteolipid protein (PLP) and myelin oligodendrocyte glycoprotein (MOG) have been detected in the cerebrospinal fluid of patients with MS $[1,17]$. Previously, in our laboratory, experiments with the use of pig spinal cord hydrolysate as the source of broad spectrum of myelin antigens to evoke oral tolerance in rats were performed [18]. In the presented experiment, we decided to use the most encephalogenic fragments of these three proteins, MBP85-97, PLP139-151 and MOG35-55, to induce a state of oral tolerance $[2,23]$.

Since peptide synthesis is expensive and involves many complicated chemical procedures, other techniques for obtaining peptides are desirable. One example is the application of food-grade lactic acid bacteria (LAB) as biofactories for the production of heterologous proteins [28]. Lactic acid bacteria are present in fermented foods, are safe for human and animal consumption, and are extensively developed as live antigen delivery systems. Heterologous expression of therapeutic proteins, such as enzymes, cytokines or antigens, allows the broad use of these bacteria in various applications [5]. For our purposes, we designed recombinant Lactococcus lactis strains for use as a mucosal antigen delivery system. As LAB are present naturally in the gastrointestinal tract, we aimed to develop a minimally invasive method to induce oral tolerance that could be further applied for MS treatment.

In our experiments, EAE was applied as an animal model of MS. As EAE is a predominantly used MS model that is based on autoimmunological aspects of the disease, it was appropriate for our investigations. Also Lewis rats used in this study are commonly employed in such experiments, being one of the strains susceptible for EAE [23,39].

Our previous results demonstrated that feeding animals a mixture of $L$. lactis lysates producing MBP8597, PLP139-151 and MOG35-55, in a twenty-fold but not a four-fold feeding scheme, could diminish the clinical symptoms of EAE [19]. In this study, we examined the influence of feeding L. lactis lysates on histo- 
Table I. Strains and plasmids

\begin{tabular}{|c|c|c|}
\hline Strain & Genotype & Source \\
\hline \multicolumn{3}{|l|}{ Lactococcus lactis } \\
\hline IBB360 & Natural isolate, characterized as an autolytic strain & IBB PAS collection \\
\hline \multicolumn{3}{|l|}{ Plasmids } \\
\hline plL253:PptcB & Ery $^{R}$, plL253 derivative with regulated ptcB gene promoter region & {$[19]$} \\
\hline pIL253:PptcB:MOG35-55 & Ery $^{R}$, plL253 derivative with ptcB gene promoter, expressing MOG35-55 antigen & [19] \\
\hline pIL253:PptcB:MBP85-97 & Ery $^{R}$, pIL253 derivative with ptcB gene promoter, expressing MBP85-97 antigen & [19] \\
\hline pIL253:PptcB:PLP139-151 & Ery $^{R}$, plL253 derivative with ptcB gene promoter, expressing PLP139-151 antigen & [19] \\
\hline
\end{tabular}

pathological changes in the CNS and serum cytokine levels in rats with EAE.

\section{Material and methods}

\section{Animals}

Three-month-old female Lewis rats, provided by the Mossakowski Medical Research Centre, Polish Academy of Sciences, Warsaw, Poland, weighing approximately $180 \mathrm{~g}$ were used in the study. The animals were provided with food and water ad libitum unless otherwise required. Experiments were conducted in accordance with EU Directive 2010/63/EU for animal experiments and based on the consent of the Fourth Local Ethics Committee for Animal Experiments in Warsaw (Act no. 66/2010 of 08.10.2010).

\section{Bacterial strains and plasmids}

Recombinant $L$. lactis derivatives of the natural isolate IBB360, and plasmids that were used in this work are listed in Table I. Construction of the plL253:PptcB recombinant vectors expressing myelin antigens MBP85-97, PLP139-151 and MOG35-55 have been described elsewhere [19].

\section{Preparation of whole-cell lysates of recombinant lactococci}

Recombinant lactococci were prepared for intragastric administration as follows. Cells were grown overnight at $30^{\circ} \mathrm{C}$ in $\mathrm{M} 17$ medium [36] supplemented with $0.5 \%$ cellobiose and erythromycin $(5 \mu \mathrm{g} / \mathrm{ml})$. Subsequently, cells were harvested (8000 g, $10 \mathrm{~min}$., $4^{\circ} \mathrm{C}$ ) and washed once with $0.9 \% \mathrm{NaCl}$. Cells were then suspended in $0.9 \% \mathrm{NaCl}$ and disrupted 3 times for 1 min using the MiniBeadbeater (BioSpec Products) and 106- $\mu \mathrm{m}$ glass beads (Sigma). Adequate dilutions of cell lysates were generated that corresponded to doses of $10^{3}$ and $10^{6}$ colony forming units (CFUs). Single doses were frozen in Eppendorf tubes in liquid nitrogen and stored at $-20^{\circ} \mathrm{C}$ until use.

\section{Study design}

A total number of 36 animals were randomly divided into 6 groups, consisting of 6 rats each. Animals with evoked EAE were fed intragastrically. Animals were given preparations containing either bacteria with empty vector (plL253:PptcB) or a mixture of bacteria producing myelin peptides (MOG35-55, MBP85-97 and PLP139-151). Both preparations were administered in two doses. As reference, a group of animals with EAE, not receiving the bacteria preparations was created. Non-treated animals served as a control group. For the time diagram of the experiment see Figure 1.

\section{Animal feeding}

Using a gauged pointed needle, animals were fed intragastrically with bacteria preparations once daily for 20 consecutive days. Animals were deprived of food two hours before administration of the bacteria. The administered preparations contained whole-cell $L$. lactis lysates diluted accordingly in $0.5 \mathrm{ml}$ saline to obtain a dose of $10^{3}$ or $10^{6} \mathrm{CFU} / \mathrm{rat}$.

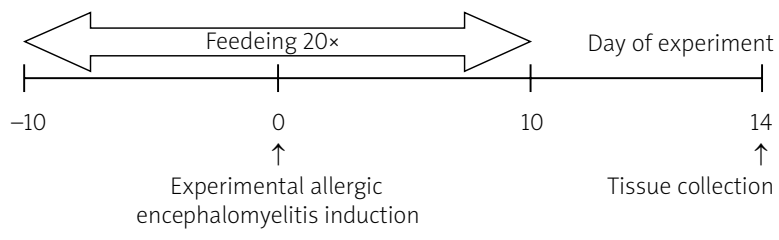

Fig. 1. Time diagram of experiment. 


\section{Experimental allergic encephalomyelitis}

Animals were immunized on the $10^{\text {th }}$ day of feeding. The day of immunization was defined as 0 days post-immunization (DPI). EAE was evoked as follows: slightly anesthetized animals (intraperitoneal injection with sodium brietal, Lilly) were injected intradermally into the hind paws with $100 \mu \mathrm{l}$ (per paw) of the immunization mixture. The mixture contained guinea pig spinal cord homogenate $(50 \%$ homogenate in PBS) with Freund's adjuvant (1:1) and Mycobacterium tuberculosis $(4 \mathrm{mg} / \mathrm{ml})$. The components were mixed well before application.

\section{Material collection}

At $15 \mathrm{DPI}$, the animals were anesthetized $(0.67 \mathrm{ml} /$ $\mathrm{kg}$ ketamine $+0.5 \mathrm{ml} / \mathrm{kg}$ xylazine i.p., Vetoquinol Biowet) and, after blood collection, perfused transcardially with $4 \%$ paraformaldehyde. Lumbar and cervical segments of spinal cords were collected from the spinal canal for histopathological analysis. Serum was obtained from the collected blood.

\section{Histopathological analysis}

The collected spinal cord fragments were embedded in paraffin and cut into 8 - $\mu$ m-thick slices. Cresyl violet staining ( $1 \%$ water solution) was performed for cell exposure. A series of labeling experiments were also performed using the sections with the following antibodies: anti-T cells (Anti-CD45RO, DAKO), antiGFAP (anti-glial fibrillary acidic protein, DAKO) and anti-endogenous albumin (rabbit IgG fraction against rat albumin, MP Biomedicals). The procedure was performed as follows: using dewaxed slices, endogenous peroxidase was blocked with $3 \%$ hydrogen peroxide, and the background was blocked with 10\% albumin. After incubation with the primary antibodies, the sections were washed and then incubated with a secondary antibody coupled to biotin. After washing, streptavidin coupled to peroxidase was applied followed by a chromogen. The sections were then stained with Mayer's hematoxylin. The chemicals were supplied by DAKO. The sections were analyzed using a light microscope (AH3, Olympus) and images were obtained using a designated camera (3-35AD-4, Olympus).

\section{Morphometric analysis}

The morphometric analysis was conducted using both lumbar and cervical spinal cord segment sec- tions stained with Cresyl violet. The area of the whole spinal cord cross-section and the area occupied by the inflammatory infiltrate were measured to determine the ratio, which is presented as the percentage of the slice area occupied by the inflammatory infiltrate.

\section{Measurement of cytokine levels}

In serum obtained from collected blood, cytokine levels (IL-1b, IL-10, TNF- $\alpha$ and IFN- $\gamma$ ) were analyzed. Analysis were made using the Bio-Plex Rat Cytokine Assay (Bio-Rad, Poland) according to the protocol supplied by the manufacturer (Bio-PlexTM Cytokine Assay Instruction Manual, Bio-Rad, Poland). Measurements were made using Luminex Bio Plex 200 analyzer, equipped with the software Manager version 5.0. (Bio-Rad, Poland).

\section{Statistical analysis}

The results are presented as means \pm SD. Statistical assessments were performed using the MannWhitney test. $P<0.05$ was considered statistically significant.

\section{Results}

\section{Histopathological studies}

Spinal cord cross-sections from control animals showed no signs of inflammation (Fig. 2A and D). Inflammatory infiltrates that were visible in both the gray and white matter of the spinal cord in rats with evoked EAE (Fig. 2B) diminished after oral administration of both doses of $L$. lactis lysates (Fig. 2C). Moreover, there were no visible differences between the intensity of the infiltrates in rats fed preparations containing lysates of bacteria producing myelin peptides and control preparations (data not shown). We also noticed that the infiltrates in animals fed bacterial lysates (both the control and the L. lactis producing myelin peptides preparations) had a reduced abundance of inflammatory cells (Fig. 2F) compared with rats with EAE (Fig. 2E), yet they occupied a similar area.

Anti-GFAP labeling revealed active astrocytes in both the gray and white matter of the spinal cord. In untreated rats, a weak reaction was observed, and the astrocytes displayed short tabs and insufficient cytoplasm (Fig. 2G), whereas rats with induced EAE were characterized by active astrocytes with long, branched tabs (Fig. 2H). After oral administration 
NT
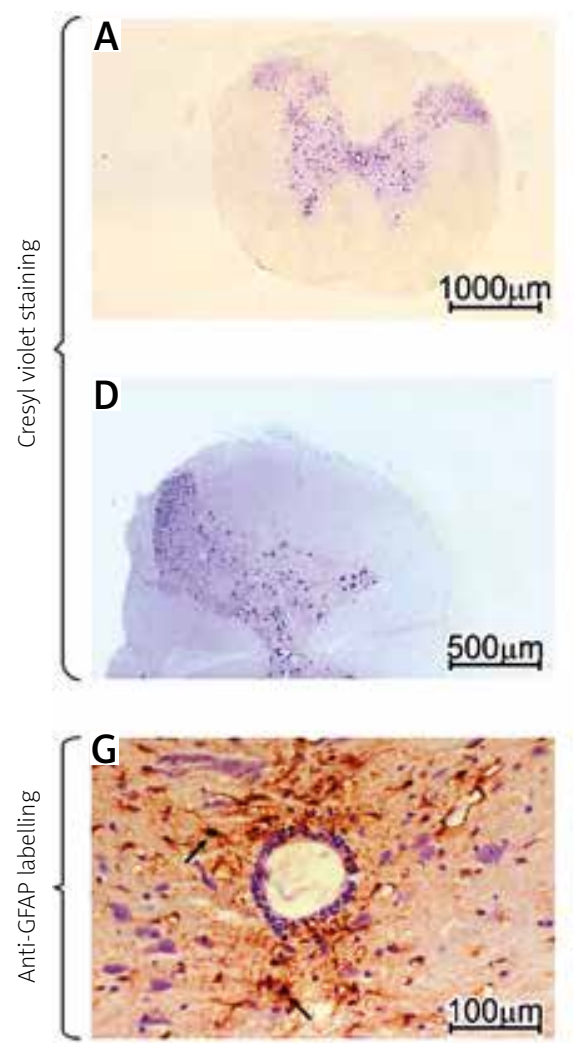

EAE
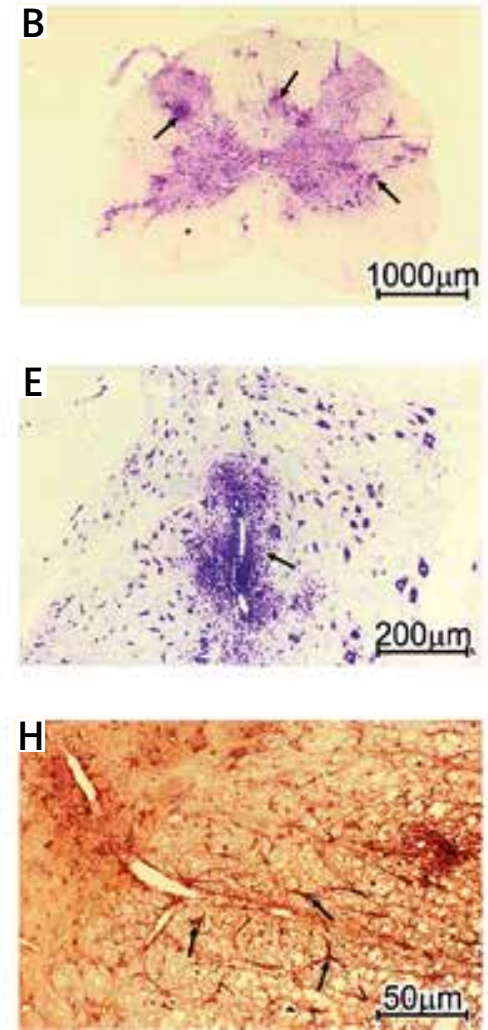

L. lactis
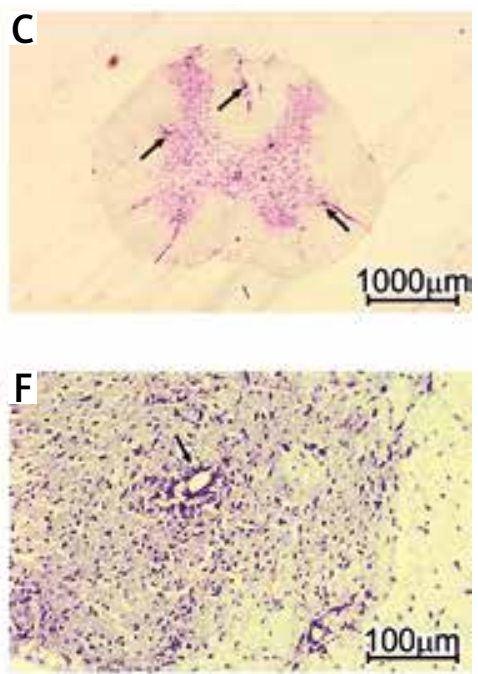

Fig. 2. Spinal cord cross-sections. Cresyl violet staining (A-F); inflammatory infiltrates are indicated by arrows. Anti-GFAP labeling (G-I); astrocytes are indicated by arrows. Non-treated animals (NT), animals with induced experimental allergic encephalomyelitis (EAE), animals with EAE fed bacteria producing myelin peptides (Lactococcus lactis), $n=6$.

of $L$. lactis lysates, the number of active astrocytes increased in rats with EAE (Fig. 2I).

Anti-endogenous albumin labeling revealed albumin in the perivascular area of rats with induced $E A E$ (Fig. 3A). T cells were observed in the area occupied by inflammatory infiltrates (Fig. 3B).

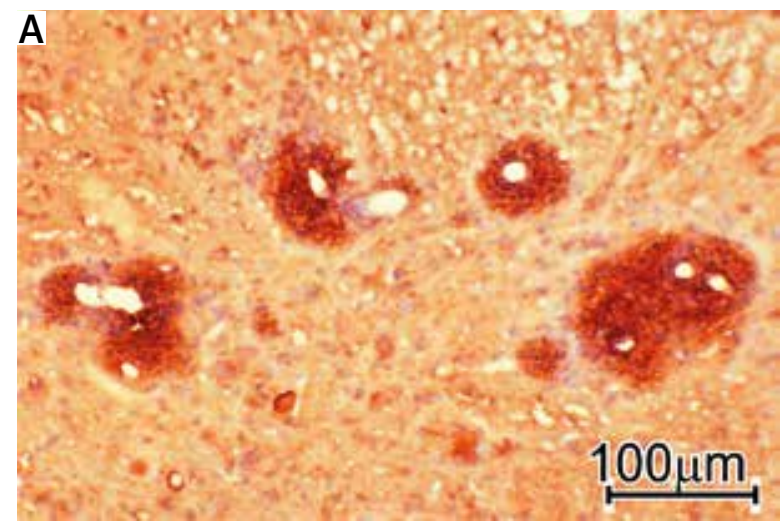

\section{Morphometric analysis}

A morphometric analysis was conducted to assess the area of the spinal cord cross-section occupied by inflammatory infiltrates. No significant differences were observed between groups of fed or non-fed rats with EAE. Animals in the experimental

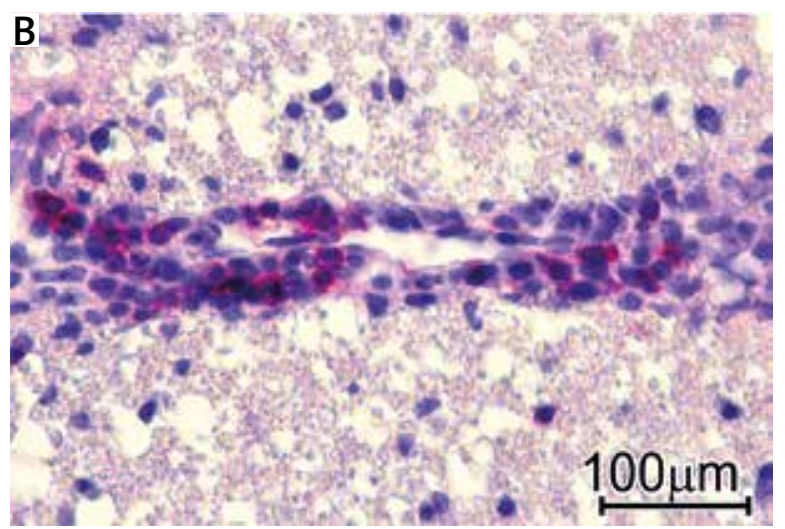

Fig. 3. Spinal cord cross-sections. Anti-endogenous albumin labeling (A). Anti-T cell labeling (B), $n=6$. 
A

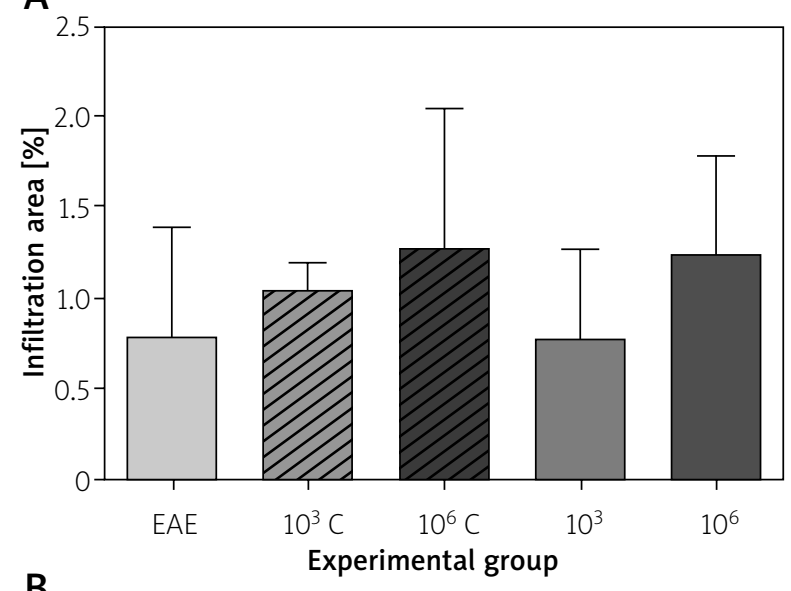

$\mathrm{B}$

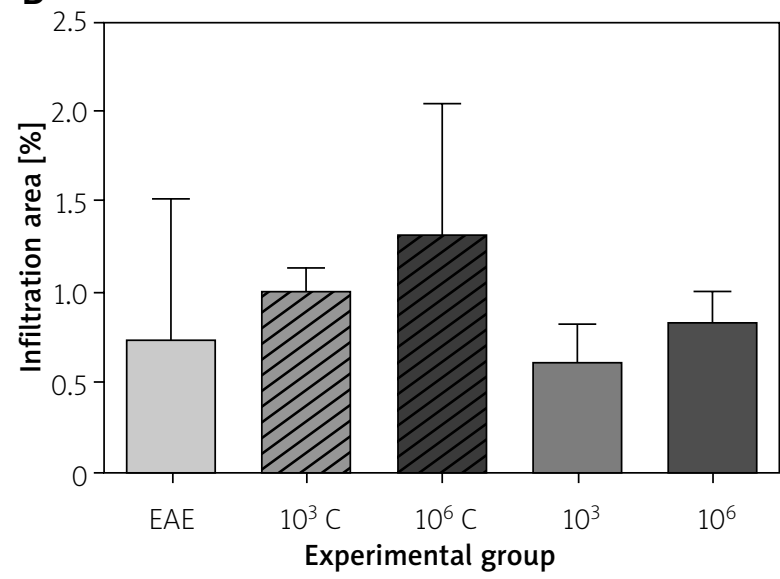

Fig. 4. Percentage of the section area occupied by inflammatory infiltrates. Cervical segment of spinal cord (A). Lumbar segment of spinal cord (B), $n=6$.

groups presented very large individual differences in the infiltration area, resulting in highly dispersive results. Therefore, the changes observed in the area occupied by inflammatory infiltrates can only be described as trends and were similar for both cervical and lumbar spinal cord segments (Fig. 4A and B). In rats that received a lower dose of the lysate $\left(10^{3}\right)$ of myelin peptide-producing bacteria, inflammatory infiltrates occupied a small area of the spinal cord cross-section, while higher dose preparations of both control $\left(10^{6} \mathrm{C}\right)$ and myelin peptide-producing bacteria $\left(10^{6}\right)$ lead to a slight increasing trend in the area occupied by inflammatory infiltrates in comparison to non-fed rats with EAE.

\section{Cytokine levels}

The induction of EAE in rats resulted in elevated levels of IL-1b, IL-10, TNF- $\alpha$ and IFN- $\gamma$ compared with non-treated animals (Fig. 5A-D). Oral administration of $L$. lactis preparations (control and bacteria producing myelin peptides) at both doses decreased IL-1b, IL-10 and TNF- $\alpha$ to levels that were similar to non-treated animals (Fig. 5A-C). The same effect was observed for rats that received control bacterial preparation. However, in the group that was fed lysates from myelin-producing bacteria, the level of IFN- $\gamma$ remained elevated and even increased slightly following the administration of preparation at the higher dose (Fig. 5D).

\section{Discussion}

Multiple sclerosis is a disease of unknown etiology. As a result, only the symptoms, and not the cause, can be treated. Current MS therapies include mostly non-specific, systemic immunosuppression, which is not free from side effects or can simply be inefficient. Other therapies may be more adequate, but they may also cause severe side effects (e.g. natalizumab) [42]. Our intention in the present study was to exploit the naturally occurring state of oral tolerance for the treatment of MS. As MS is an autoimmune disease in which autoreactive $T$ lymphocytes destroy the myelin sheath, the induction of oral tolerance, which decreases the systemic immunoresponse to previously fed antigen, may be an interesting therapeutic alternative. Gut-associated lymphoid tissue (GALT) produce anti-inflammatory cytokines providing the immunosuppressive environment, helping to maintain the state of tolerance for antigens from food or commensal bacteria. Dendritic cells in the GALT present the gut-derived antigens to naïve T cells in Peyer's patches, what results in differentiation of $T$ cells into regulatory $T$ cells (Tregs) producing IL-10 and TGF- $\beta$, or internalization of TCR leading to anergy. Thus, orally administered fragments of myelin peptides induce, depending on the antigen dose, active suppression (inhibiting of Th1-dependent immunoresponse) or anergy/clonal deletion of responsive T lymphocytes (both Th1 and Th2) in the mucosal immune system $[4,27,40]$. Anergic $T$ cells are not able to migrate from the site of tolerance induction, and remaining in the GALT produce anti-inflammatory cytokines. Tregs induced in the Peyer's patches pass into the bloodstream and spread the antigen-specific tolerance throughout the body. Additionally, apoptosis of autoreactive $T$ cells is induced in the thymus after oral administration of the autoantigen $[27,34]$. This process results in 
A

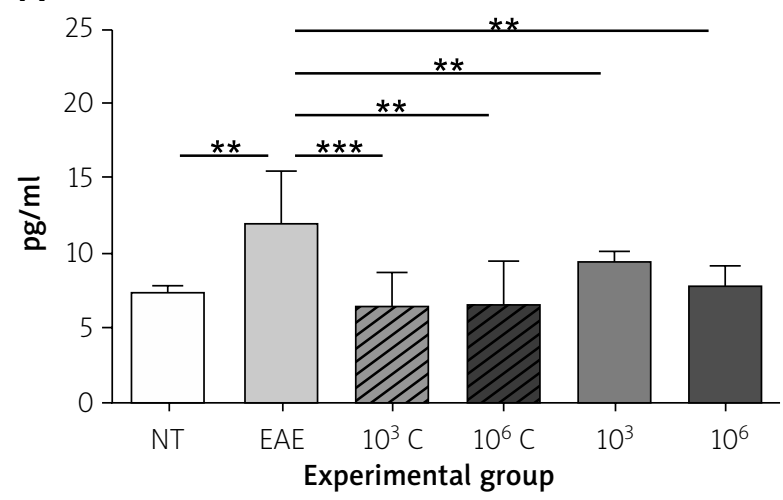

C

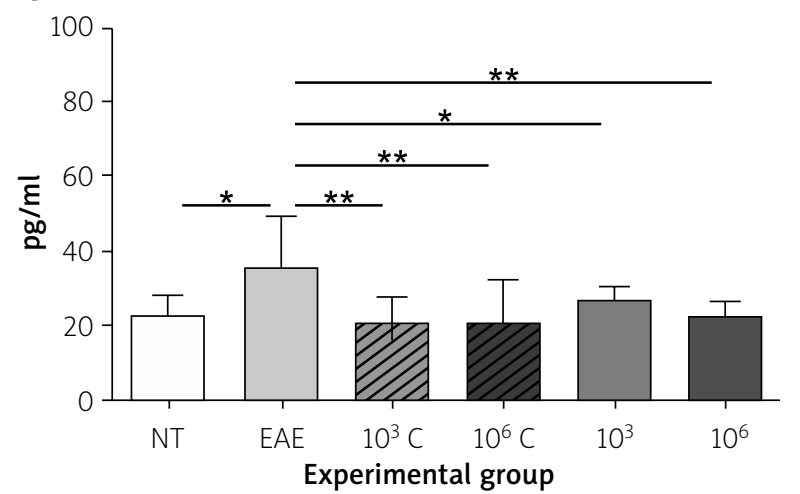

B

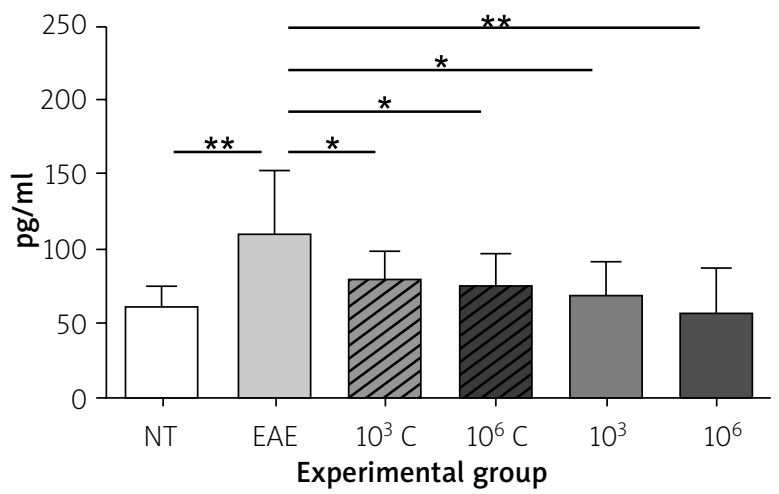

D

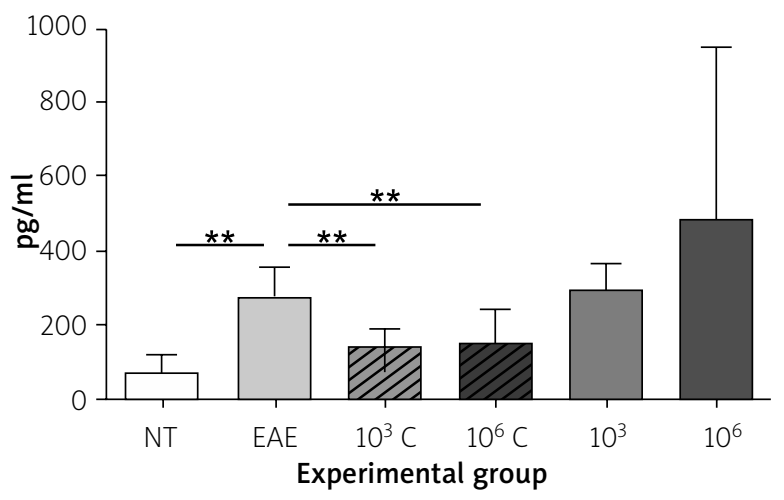

(B), TNF- $\alpha$ (C), and IFN- $\gamma($ D), $n=6$.

[6]. Additionally, feeding with ovalbumin-secreting L. lactis has been reported to induce ovalbumin tolerance in mice. Furthermore, mice that received L. lactis alone were able to mount a slight immune response, indicating that this bacterial species itself can enhance the induction of oral tolerance $[16,25]$.

We have previously shown that twenty-fold, but not four-fold, oral administration of a mixture of lysates from L. lactis producing MBP85-97, PLP139-151 and MOG35-55 in two doses of $10^{3}$ and $10^{6} \mathrm{CFU}$ per dose reduces clinical symptoms and body mass drop in rats with EAE [19]. Here, we describe the effects of bacterial lysates on some neuroimmunological parameters of induced EAE, an animal model of MS. During the progression of EAE, the blood-brain barrier opens. This phenomenon is consistent with the theory regarding the mechanism responsible for the development of MS, in which autoreactive T cells migrate into the CNS and induce an inflammatory response against myelin epitopes $[13,24]$. Our histopathological analysis of the spinal cord cross-sections demonstrated that evoking EAE resulted in the appearance of perivascular infiltrates in the CNS. Anti-endoge- 
nous albumin labeling revealed its proximity to the vessels, confirming the opening of the blood-brain barrier. T-cell labeling showed that the infiltrates consisted of those immune cells. In our experiments, the inflammatory process observed after evoking EAE in rats was diminished by oral administration of $L$. lactis lysates. The decrease in inflammation intensity was manifested by a reduced number of immune cells rather than by a smaller infiltration surface.

Anti-GFAP labeling was performed to expose active astrocytes. The induction of EAE resulted in an increase in the activity of a greater number of astrocytes, as compared with control rats, and feeding the animals with bacterial lysates further increased the number of these cells. This phenomenon could account for the increased astrocyte proliferation associated with repair processes and glial scar formation in the CNS $[26,30]$.

Serum cytokine levels were measured to determine the peripheral immunological state of the animals $[20,31,33]$. The results showed that the induction of EAE resulted in an increase in all measured cytokine levels, including both pro- and anti-inflammatory cytokines. Feeding animals with recombinant $L$. lactis lysates decreased IL- 1 b, IL-10 and TNF- $\alpha$ to the levels detected in non-treated animals, which could imply that animals fed bacterial preparations did not develop an immune reaction. However, this explanation is inconsistent with the histopathological analysis showing infiltration into the CNS. CNS inflammation must be a result of a peripheral process because the immunization mixture was injected peripherally (paw pads). Therefore, it is more likely that our results capture the moment when the inflammatory process was completely cleared in the periphery but still present in the CNS. Differences in the reaction time of the peripheral versus the central immune system may result from the initial induction of antigen tolerance in the gut mucosa, followed by the periphery and then the CNS [29].

Interesting effects have been documented with respect to IFN- $\gamma$. After EAE induction, IFN- $\gamma$ was elevated in comparison to non-treated animals, and feeding with control bacterial preparations resulted in decreased IFN- $\gamma$ levels. However, when the animals were fed either dose of the bacterial lysate producing myelin peptides, the level of IFN- $\gamma$ remained elevated. Previous investigations have shown that IFN- $\gamma$ influences apoptosis of autoreactive T cells by astrocytes $[14,32]$, which may underlie the reduced number of inflammatory cells observed in the infiltrates in rats fed bacterial lysates.

An important observation was made with respect to the effect of oral administration of lysates containing L. lactis cells carrying the empty vector (plL253:PptcB). Results showed that the control preparation may produce a similar but less intense effect in rats as lysates from bacteria producing myelin antigens. It is known that lactococcal cells themselves are able to enhance immunotolerance in mucosa. Our observations are similar to those of Lavasani et al. [22] who showed that, due to their immunomodulatory activity and ability to induce regulatory $T$ cells, three probiotic lactic acid bacteria strains (L. paracasei, L. plantarum DSM 15312 and L. plantarum DSM 15313) could be helpful for the treatment of autoimmune diseases.

Difficulties associated with the development of effective MS therapy are linked to the observation that almost every patient presents a unique course of the disease [21]. Similarly, in experimental animals, even inbred animal lines, the clinical symptoms will differ among individual cases. In our trials, EAE was induced using guinea pig spinal cord homogenate as the source of myelin antigens to imitate MS, in which many encephalogenic antigens are believed to play a role. Our previous study has also shown that the three main myelin peptide fragments selected to induce oral tolerance appear to be effective [19].

Experimental results in this work indicate that L. lactis is a good antigen delivery system for the induction of oral tolerance in animals with EAE. This notion is confirmed not only by the diminished clinical symptoms of the ongoing disease but also by the decreased inflammatory activity. We suggest that oral administration of lysates from recombinant L. lactis cells accelerates the resolution of peripheral inflammation, decreases the intensity of inflammation in the CNS, and boosts the repair process. Considered together, these phenomena may elucidate a perspective for further development of this approach in MS therapy.

\section{Acknowledgements}

This work was supported by the Ministry of Science and Higher Education grant no. N302 009 32/1139.

First author has been supported by a scholarship from the European Social Fund, Human Capital Operational Programme. 


\section{Disclosure}

\section{Authors report no conflict of interest.}

\section{References}

1. Abott JD, Blanchfield JL, Martinson DA, Russel SC, Taslim N, Curtis AD, Mannie MD. Neuroantigen-specific, tolerogenic vaccines: GM-CSF is a fusion partner that facilitates tolerance rather than immunity to domminant self-epitopes of myelin in murine models of experimental autoimmune encephalomyelitis (EAE). BMC Immunol 2011; 12: 72

2. Adelmann M, Wood J, Benzel I, Fiori P, Lassman H, Matthieu JM, Gardinier MV, Dornmair K, Linington C. The N-terminal domain of the myelin oligodendrocyte glycoprotein (MOG) induces acute demyalinating experimental autoimmune encephalomyelitis in the Lewis rats. J Neuroimmunol 1995; 63: 17-27.

3. Axtell RC, de Jong BA, Boniface $K$, van der Voort LF, Bhat R, De Sarno P, Han M, Zhong F, Castellanos JG, Mair R, Christakos A, Kolkowitz I, Katz L, Killestein J, Polman CH, de Waal Malefyt R, Steinman L, Raman C. T helper type 1 and 17 cells determine efficacy of IFN- $\beta$ in multiple sclerosis and experimental autoimmune encephalomyelitis. Nat Med 2010; 16: 406-412.

4. Benson JM, Campbell KA, Guan Z, Gienapp IE, Stuskman SS, Forsthuber T, Whitacre CC. T-cell activation and receptor downmodulation precede deletion induced by mucosally administered antigen. J Clin Invest 2000; 106: 1031-1038.

5. Bermudez-Humaran LG. Lactococcus lactis as a live vector for mucosal delivery of therapeutic proteins. Hum Vaccin 2009; 5: 264-267.

6. Bermudez-Humaran LG, Nouaille S, Zilberfarb V, Corthier G, Cruss A, Langella P, Issad T. Effects of intranasal administration of a leptin-secreting Lactococcus lactis recombinant on food intake, body weight, and immune response of mice. Appl Environ Microbiol 2007; 73: 5300-5307.

7. Bielekova B, Richert N, Blevins G, Markovic-Plese S, McCartin J, Frank JA, Würfel J, Ohayon J, Waldmann TA, McFarland HF, Martin R. Humanized anti-CD25 (daclizumab) inhibits disease activity in multiple sclerosis patients failing to respond to interferon $\beta$. Proc Natl Acad Sci U S A 2004; 101: 8705-8708.

8. Castro-Borrero W, Graves D, Frohman TC, Bates Flores A, Hardeman P, Logan D, Orchard M, Greenberg B, Frohman EM. Current and emerging therapies in multiple sclerosis: a systemic review. Ther Adv Neurol Disord 2012; 5: 205-220.

9. Coles AJ. Alemtezumab therapy for multiple sclerosis. Neurotherapeutics 2013; 1: 29-33.

10. Dąbrowska-Bouta B, Stróżyńska L, Chalimoniuk M, FrontczakBaniewicz M, Sulkowski G. The influence of glutamatergic receptor antagonists on biochemical and ultrastructural changes in myelin membranes of rats subjected to experimental autoimmune encephalomyelitis. Folia Neuropathol 2015; 53: 317-326.

11. Faria AMC, Weiner HL. Oral tolerance: implications for autoimmune diseases. Clin Dev Immunol 2006; 13: 143-157.

12. Fletcher JM, Lalor SJ, Sweeney CM, Tubridy N, Mills KHG. T cells in multiple sclerosis and experimental allergic encephalomyelitis. Clin Exp Immunol 2010; 162: 1-11.
13. Franklin RJ, Ffrench-Constant C, Edgar JM, Smith KJ. Neuroprotection and repair in multiple sclerosis. Nature reviews. Neurology 2012; 8: 624-634.

14. Hara H, Nanri Y, Tabata E, Mitsutake S, Tabira T. Identification of astrocyte-derived immune suppressor factor that induces apoptosis of autoreactive T cells. J Neuroimmunol 2011; 233: 135-146.

15. Higgins PJ, Weiner HL. Supression of experimental autoimmune encephalomyelitis by oral administration of myelin basic protein and its fragments. J Immunol 1988; 140: 440-445.

16. Huibregste IL, Snoeck V, de Creus A, Braat H, De Jong EC, Van Deventer SJ, Rottiers P. Induction of ovalbumin-specific tolerance by oral administration of Lactococcus lactis secreting ovalbumin. Gastroenterology 2007; 133: 517-528.

17. Jurynczyk M, Walczak A, Jurewicz A, Jesionek-Kupnicka D, Szczepanik M, Selmaj K. Immune regulation of multiple sclerosis by transdermally applied myelin peptides. Ann Neurol 2010; 68: 593-601.

18. Kasarello K, Gadamski R, Piotrowski P, Kurzepa K, Kwiatkowska-Patzer B, Lipkowski AW. Effect of oral administration of pig spinal cord hydrolysate on clinical and histopathological symptoms of experimental allergic encephalomyelitis in rats. Folia Neuropathol 2015; 53: 128-138.

19. Kasarello K, Kwiatkowska-Patzer B, Lipkowski AW, Bardowski JK, Szczepankowska AK. Oral administration of Lactococcus lactis expressing synthetic genes of myelin antigens in decreasing experimental autoimmune encephalomyelitis in rats. Med Sci Monit 2015; 21: 1587-1597.

20. Lalor SJ, Dungan LS, Sutton CE, Basedo SA, Fletcher JM, Mills KH. Caspase-1-processed cytokines IL-1 $\beta$ and IL-18 promote IL-17 production by $\gamma \delta$ and CD4 T cells that mediate autoimmmunity. J Immunol 2013; 186: 5738-5748.

21. Lassmann H, van Horssen J, Mahad D. Progressive multiple sclerosis: pathology and pathogenesis. Nature Reviews. Neurology 2012; 8: 647-656.

22. Lavasani S, Dzhambazov B, Nouri MA, Fak F, Buske S, Molin G, Thorlacius H, Alenfall J, Jeppsson B, Weström B. A novel probiotic mixture exerts a therapeutic effect on expreimental autoimmune encephalomyelitis mediated by IL-10 producing regulatory T cells. PLoS One 2010; 5: 1-11.

23. Link H, Xiao BG. Rat models as tool to develop new immunotherapies. Immunol Rev 2001; 184: 117-128.

24. Lyck R, Engelhardt B. Going Against the tide - how encephalogenic T cells breach the blood-brain barrier. J Vasc Res 2001; 49: 4497-4509.

25. Maillard MH, Snapper SB. Teaching tolerance with a probiotic antigen delivery system. Gastroenterology 2007; 133: 706-709.

26. Meyer AL, Benson JM, Giennap IE, Cox KL, Whitacre CC. Supression of murine chronic relapsing experimental autoimmune encephalomyelitis by the oral administration of myelin basic protein. J Immunol 1996; 157: 4230-4238.

27. Mirenda V, Millington O, Lechler RI, Scott D, Hernandez-Fuentes MP, Read J, Tan PH, George AJT, Garside P, Marelli-Gerg FM. Tolerant T cells display impaired trafficking ability. Eur I Immunol 2005; 35: 2146-2156.

28. Morello E, Bermudez-Humaran LG, Llull D, Sole V, Miraglio N, Langella P, Poquet I. Lactococcus lactis, an efficient cell fac- 
tory for recombinant protein production and secretion. J Mol Microbol Biotechnol 2008; 14: 48-58.

29. Pabst O, Mowat AM. Oral tolerance to food protein. Mucosal Immunol 2012; 5: 232-239.

30. Reynolds R, Roncaroli F, Nicholas R, Radotra B, Gveric D, Howell $O$. The neuropathological basis of clinical progression in multiple sclerosis. Acta Neuropathol 2011; 122: 155-170.

31. Rodgers JM, Miller SD. Cytokine control of inflammation and repair in the pathology of multiple sclerosis. Yale J Biol Med 2012; 85: 447-468.

32. Sanvito L, Constantinescu CS, Gran B, 't Hart BA. The Multifaceted Role of Interferon- $\gamma$ in Central Nervous System Autoimmune Demyelination. The Open Autoimmunity Journal 2010; 2: 151-159.

33. Sharief MK, Hentges R. Association between tumor necrosis factor-alpha and disease progression in patients with multiple sclerosis. N Engl J Med 1991; 325: 467-472.

34. Song F, Wardrop RM, Giennap IE, Stuckman SS, Meyer AL, Shawler T, Whitacre CC. The Peyer's patch is a critical immunoregulatory site for mucosal tolerance in experimental autoimmune encephalomyelitis (EAE). J Autoimmun 2008; 30: 230-237.

35. Sospedra M, Martin R. Immunology of multiple sclerosis. Annu Rev Immunol 2005; 23: 683-747.

36. Terzaghi BE, Sandine WE. Improved medium for lactic streptococci and their bacteriophages. Appl Microbiol 1975; 29: 807-813.

37. Wardrop RM, Whitacre CC. Oral tolerance in the treatment of inflammatory autoimmune diseases. Inflamm Res 1999; 48: 106-119.

38. Weiner HL. Oral tolerance: immune mechanisms and treatment of autoimmune diseases. Immunol Today 1997; 18: 335-343.

39. Wekerle H, Kurschus FC. Animal models for multiple sclerosis. Drug Discov Today: Disease Models 2006; 3: 359-367.

40. Wells JM, Rossi O, Meijerink M, Baarlen van P. Epithelial crosstalk at the microbiota-mucosal interface. Proc Natl Acad Sci U S A 2011; 108: 4607-4614

41. Whitacre CC, Gienapp IE, Orosz CG, Bitar DM. Oral tolerance in experimental autoimmune encephalomyelitis. III. Evidence for clonal anergy. I Immunol 1991; 147: 2155-2163.

42. Ziemssen T, Ziemmssen F. The role of the humoral immune system in multiple sclerosis (MS) and its animal model experimental allergic encephalomyelitis (EAE). Autoimmun Rev 2010; 4: 460-467. 